\title{
Social risk map. The design of a complementary methodology to vulnerability indexes applied to urban regeneration activity
}

\author{
Ana Ruiz-Varona, Jorge León-Casero \\ AOS Research Group. Universidad San Jorge. Zaragoza. Spain \\ E-mail: nruiz@usj.es, jleon@usj.es
}

\begin{abstract}
Conception of urban intervention in the city is increasingly mutating from a physical urban renewal to an integrated urban approach. That is to say, measures concerning physical urban renewal should be combined with measures promoting education, economic development, social inclusion and environmental protection (European Commission, 2014). Current methodologies applied to the analysis of potential distressed areas are based on quantitative variables. The combination of these variables into a matrix characterizes the areas of the city that are subjected to different grades of intervention in terms of urban vulnerability and social exclusion. However, literature demonstrates that there are still few tools capable of measuring spatially which areas are the most sensitive to the decline in social relations within the city. Research on social maps suggests that potential attractors and risk areas can be identified from the design of a methodology based on the social perception of the public space. The application of this methodology to different case studies at the neighborhood level shows the correlation between urban vulnerability approach (quantitative) and social perception (qualitative). Indeed, perception and characterization of social risk areas empowers current urban vulnerability indicators for the integrated urban approach. Findings validate the utility of this methodology for the implementation of this model to cities and illustrate the social sphere of analysis as a platform from which to assess risk in urbanized areas.
\end{abstract}

Keywords: Urban degradation, social exclusion, qualitative methods.

\section{Introduction}

The quantity, quality and location ofnewhousing in the city concerns affordability, urbanity and social equity. Principles for regulating urban redevelopment and regeneration that enable more housing construction are necessary. Current methodologies that guide this activity often are based on socio-demographic, economic, residential characteristics and environmental features. The combination of these variables into a matrix characterizes the areas of the city that are subjected to different grades of intervention in terms of urban vulnerability and social exclusion. However, the experience in planning practice gives little empirical evidence about where, how and why redevelopments occur, and the odds that a given residential area is renewed and regenerated are not always directly correlated to the highest levels of vulnerability or social exclusion that these methodologies attempt to identify.

From 70s onwards, it is argued that studies focused on the social indicators approach. To expand on their efforts, they needed to understand the social structure and residential function within the city 'from a more systematic rather than common sense point of view' (De Miguel, Díez y Medina, 1976). This work constitutes first sociological analysis references applied to planning experience in Spain. In this regard, the extant scholarship has examined whether this model might contribute enhancement of urban vulnerability analysis 
methodologies. Studies has demonstrated understanding of vulnerability and social exclusion operative notion from those matrix of indexes referred gives emphasis to poverty, inequality, scarcity items and the tendency from which they have been passed down through the family unit.

Urban policies and measures for the distressed urban areas enhancement address a strategic change two decades later. The European context fosters and funds a specific line of action in which vulnerability notion is reviewed (Alguacil, 2006). In this regard, this is a critical shift, as the interest relies on setting the spatial limits of not only declining economic development areas, but social inclusion and environmental protection as well (OCDE, 1998; European Commission, 2014). Dwelling size, consumption rate are not ignored but reinforced by other urban scale variables: open space areas, environmental landscape, road networks, accessibility and proximity to complementary uses to the residential ones. Further, studies focus on the definition and measurement of different grades of intervention in order to provide an urban area gradation for their effective urban regeneration. Some of this contemporary research on the urban area gradation intends priority areas to be targeted analysis model by underlying physical, social, economic and political factors (The Ministry of Public Works and Transport, 1990; Hernández Aja et al., 2013). An enhancement and review of this methodological approach is documented with regard to the analysis of specific urban regeneration neighborhoods (Bruquetas, M., Moreno, F-J., Walliser, A., 2005). In any case, main action does not delve into the family unit but the urban scale.

In this context, criteria for the declining areas become the key point from which urban policies are designed and the reference that enables planning practice in terms of urban regeneration activity (Atkinson, Cantillon, Marlier and Nolan, 2002). However, more research is needed to determine how these criteria interact to shape the dynamics of urban intervention in terms of urban vulnerability and social exclusion. A better and updated knowledge in terms of methodological tools and procedures from where to design urban regeneration programs (from a physical urban renewal to an integrated urban approach) becomes a contribution to achieve useful policy goals of integrating distressed urban areas.

Álvarez-Mora and Roch (2010) find that evidences for the implementation of urban regeneration actions refer not only to the physical degradation of dwellings and buildings or new public space and facilities, but to the increase of social inequalities and resources, such as poverty, low educational level, social exclusion or economically distressed communities. They point out that these approach demands long-term actions for the effectiveness of the integral urban regeneration. Temes (2014) argues that social exclusion notion requires a methodology based on a statistical multivariable analysis in order to determine a more effective and efficient set of synthetic indicators in terms of integral vulnerability. Ruiz and Alfaro (2017) have documented that the adaptability degree of the variables that characterize integral vulnerability is important issue that should take its place in methodologies on integrating distressed urban areas selection and policy analysis. The authors find evidences that some other complementary tool oriented towards their enhancement in a long-term perspective is required when distressed urban areas that do not correspond to the ones in which the adaptability degree is highest. That is to say, the study provides information on whether urban regeneration activity should include some other complementary actions to the physical degradation of dwellings and buildings or new public space and facilities.

However, little research has directly studied integral vulnerability from a social sphere of analysis. Yet, research on social perception as a qualitative approach is scant. At the beginning of the decade work provides some support for the construction of social exclusion measurement tools from a social work perspective (Raya, 2010). Connections are establishes between shaping social support networks in a discontinuous urban spaces (Muster and Murie, 2004) and the role of neogeography and digital divide (Haklay, 2013; Rana y Joliveau, 2009). A better understanding of the influence of social relations within the 
city is important because it would add to our knowledge of the underlying mechanisms that social exclusion distributes unevenly across urban space.

Research on social spheres highlights the importance of social support networks (family unit, neighbors or ethnic minorities) as a priority resource in dealing with processes of social exclusion. Because it especially influences social welfare and employment opportunities, the attention to them cannot be ignored. Decrease of family unit, individualization and reduction of mutual dependence in daily life can contribute to the weakening of these social support networks.

In this article we focus on the need to characterize and measure these social support networks from an operative and the field observation perspective in which they take place. Cartography turns into a proper tool in order to evaluate and measure the strength of social support networks so as to conclude potential risk that will affect anyone in a specific urban context. We investigate this question through a qualitative analysis of how social support networks that were identified from a social perception point of view operate in Zaragoza area. Consistent with previous research (Cámara, León and Ruiz, 2016) we find a positive relationship between urban vulnerability approach (quantitative) and social perception (qualitative). Indeed, perception and characterization of social risk areas empowers current urban vulnerability indicators for the integrated urban approach.

\section{Research on social maps}

A georeferencing analysis raises thematic information from field work the possibility to identify how these social support networks shape. Social Risk maps and Geographic Information Systems (GIS) turn into an essential tool to visualize social life in a built urban environment. Initially, some experiences that introduce social map notion refer to the implementation of quantitative multivariate analysis in the socio-territorial study of local cases (Torres, 1993). Recently, this social map

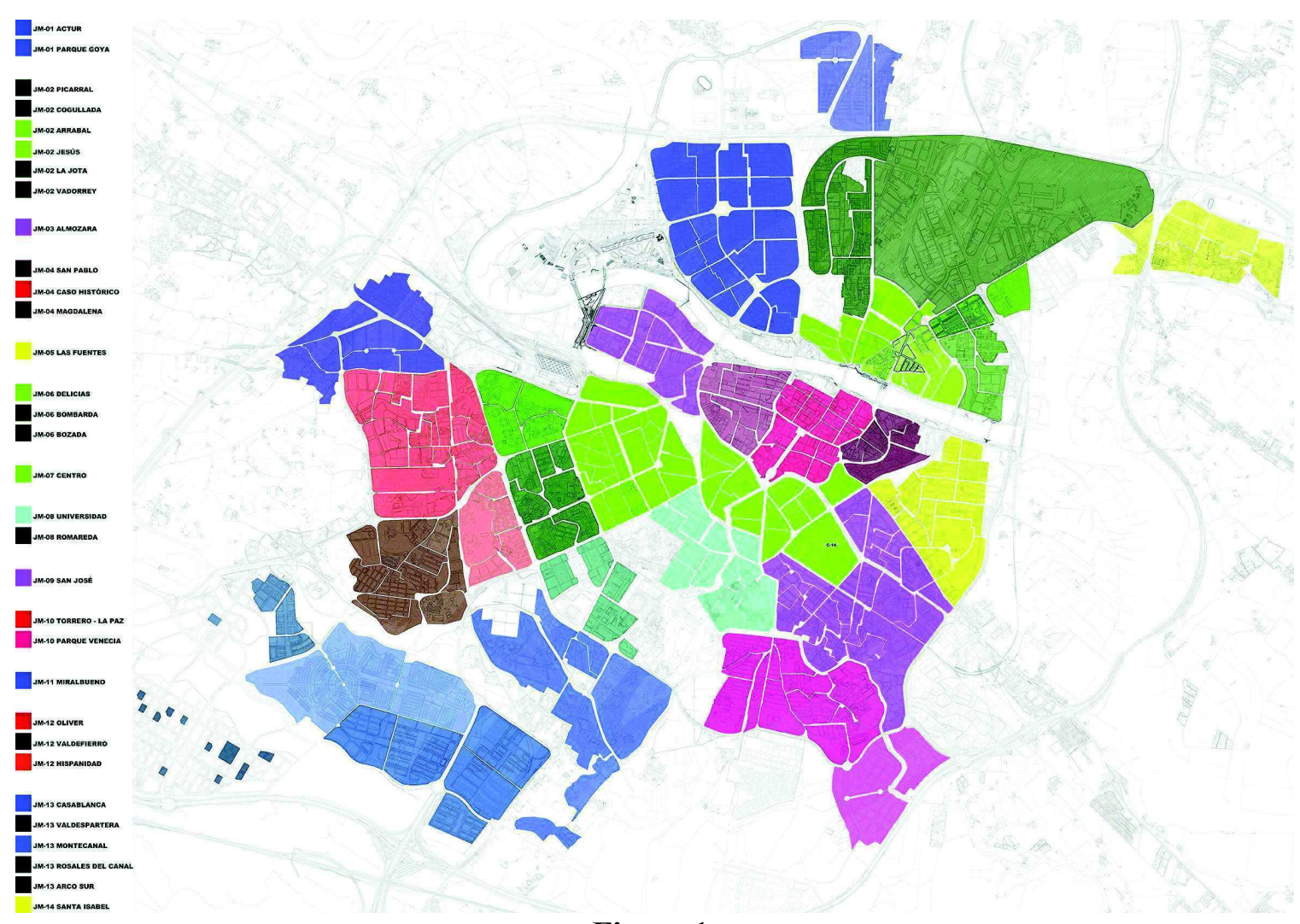

Figure 1.

Neighborhoods and districts in Zaragoza. 


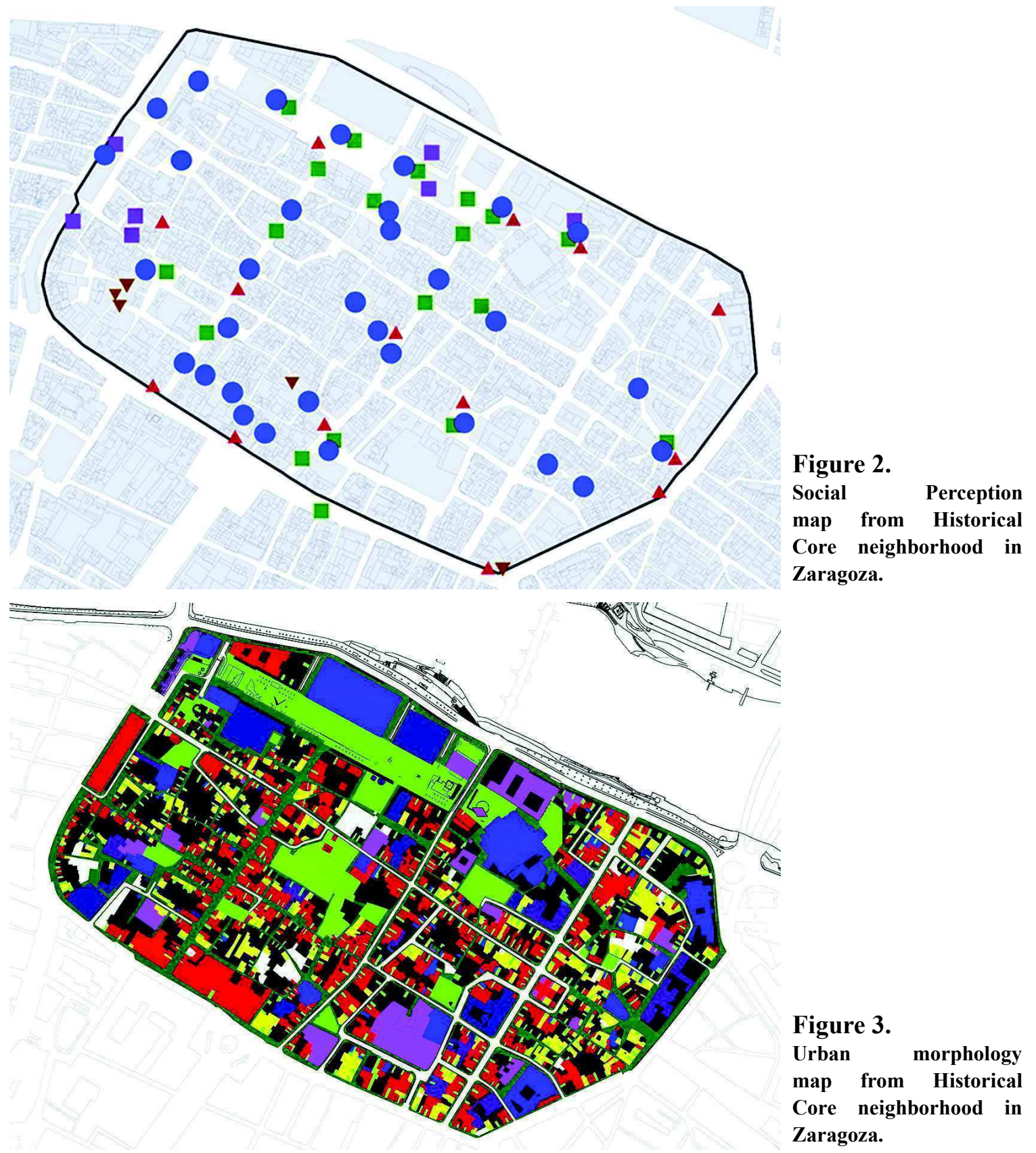

approach has been specifically intensified through the study of how urban areas interact in terms of unprecedented volumes of data (Goodchild, 2016). In this article we investigate the correlation between demographic, socioeconomic and residential quantitative approach and social perception qualitative one. Indeed, perception and characterization of social risk areas empowers current urban vulnerability indicators for the integrated urban approach.

\section{Neighborhood social perception}

The methodology takes into account primary units of analysis. In this regard, it is not considered the administrative divisions (district, postal code, census tract) in which public databases are organized but the neighborhood unit. It is at this level where subjective identity hegemonic formations take place, where spatial belonging sense arises. 
Additionally, it is at the neighborhood level where, from a social perspective, common daily relations draw minimum spatial unit from where to achieve self-sufficient necessities. This autonomy, in terms of social reproduction, is not only recognized as the required nonspecialized daily goods and services, but as the social networks that underlie in daily life as well. Indeed, lack of services and retail markets and shops in a specific urban area makes people expand their social network to a different area where these services and retail activity take place, so that these items turn into urban attractors for a wider social support network.

We study the city of Zaragoza for the application of social perception approach. The city is divided in 32 neighborhoods, officially corresponding to the 14 districts referred in Figure 1. 1.922 samples were collected corresponding to all studied neighborhoods from June 2013 to November 2016.

\section{Measurement and analysis: data and methods}

Social risk impact and measurement is undertaken from a qualitative perception focusing on results not only from a statistical point of view, but also on why situations take place and what are the social consequences of those situations. The study develops two lines of research in order to get this aim.

On the one hand, we design a report of how public space works in each of the neighborhoods. Data is constructed from an observation script together with structured interviews to key informants (García-Bueno, 2017). This sample is designed on maps (Figure

2) in a way that can be compared spatially to visibility, ground floor activities and uses in the city (Figure 3). Main content to be analyzed in order to characterize social support network and social risk at the neighborhood level refers to four categories: urban attractors, spontaneous or institutionalized neighborhoods activities, social conflicts and non-accessible or physically damaged urban areas.

-Urban attractors are understood as specific urban environment areas that usually work - either continuous or temporarily- as meeting places and enhance social interaction. However, these urban attractors do not always denote a positive effect to daily social networks; they also can generate a negative impact. It is considered negative when they match with social risk areas, that is to say, when people presence in those areas is perceived as a threat to the others (marginal, illegal or scandalous behavior). Likewise, lack of urban attractors in a neighborhood may mean inexistence of social networks and, as a consequence, a potential social risk factor.

-The study of neighborhoods activities allow us to distinguish those organized by neighbors themselves (spontaneous) through autonomous organizations from those organized by public administration (institutionalized). In any case, these activities focus on public space itself, that is to say, they constitute the social production of that referred space at the neighborhood level.

-Detection of social conflicts allows us to understand insecurity perceptions from those who inhabit the neighborhood or from those who interacts with people from that neighborhood. Real insecurity effects caused by either real or perceived social risks turns an area into a stigmatized place and makes it negative in terms of social networks and daily life activity.

-Criteria from where to identify nonaccessible or physically damaged urban areas correspond to those areas in which urban continuity is not guarantee, there is a lack of visibility, or where derelict buildings, abandoned areas, urban voids and vacant plots locate.

On the other hand, given the performative character of social network strengthening, this first line of research is complemented with the design of a synthetic index so as to evaluate the subjective perception of inhabitants. This index is defined as Subjective Potential Urban Self-Regeneration Index (SPUR). It refers the strength of social support network, the urban appropriation of space by the neighbors and the capacity to prevent social exclusion.

One innovative feature provided by this index delves into the idea that public space is not an indifferent to reality, homogeneous and geometric mass in which excluded communities 
should be integrated, but a socially produced space by these communities (Lefebvre, 1974; Logan and Molothc, 2007). As a result, it is social networks that shape public space the ones in which existence or lack of social exclusion notion should be investigated. SPUR index does not focus on public space as a physical item. It underlines social networks -within the neighborhood and the entirely city- capable of providing a certain degree of self-sufficiency for the daily life social reproduction.

Database is obtained from field work where inhabitants' daily habits have been analyzed. The design of the survey comprises 36 questions grouped in different thematic areas. The unit of analysis for the survey is the neighborhood level. Taken into account that there are no population statistics at the neighborhood level (only at the census tract and district levels), the study refers the district level as the reference that guarantees the size of samples of finite population to be made for each of the neighborhoods (Cámara, León and Ruiz, 2016).

Yet, to measure social production of space, we build three partial indexes. These indexes are constructed from a response to different items that ask about the grade of public space appropriation, the grade of social selfsufficiency and the grade of social services satisfaction (Figure 4). The sum of these three indexes is used to determine whether

\begin{tabular}{|c|c|c|}
\hline Partial index & Thematic area & Variable \\
\hline \multirow{11}{*}{$\begin{array}{c}\text { Public Space } \\
\text { Appropriation Index } \\
\text { (PSAI) }\end{array}$} & \multirow{3}{*}{ Neighborhood } & Identification degree with the neighborhood \\
\hline & & Lives in the neighborhood \\
\hline & & Works in the neighborhood \\
\hline & \multirow{3}{*}{ Oopen space } & Parks, quantity and quality \\
\hline & & Squares, quantity and quality \\
\hline & & Real/ Ideal public space property \\
\hline & \multirow{3}{*}{ Culture } & Inhabitants chance to propose activities \\
\hline & & Public administration chance to propose activities \\
\hline & & $\begin{array}{l}\text { Possibility to carry out activities in an enabled / any public } \\
\text { space }\end{array}$ \\
\hline & Security & Day / night security perception \\
\hline & $\begin{array}{l}\text { Other } \\
\text { neighborhoods }\end{array}$ & Willingness to move to another neighborhoods \\
\hline \multirow{7}{*}{$\begin{array}{c}\text { Social Self- } \\
\text { Sufficiency Index } \\
\text { (SSI) }\end{array}$} & \multirow{2}{*}{ Consumption } & Shopping frequency in the neighborhood \\
\hline & & Commercial retail quantity and quality \\
\hline & \multirow{5}{*}{$\begin{array}{l}\text { Social } \\
\text { relationships }\end{array}$} & Number of friends and acquaintances in the neighborhood \\
\hline & & Leisure frequency in the neighborhood \\
\hline & & Association belonging \\
\hline & & Location of associations \\
\hline & & Assessment of the cultural agenda \\
\hline \multirow{8}{*}{$\begin{array}{c}\text { Social Services } \\
\text { Satisfaction Index } \\
\text { (SSSI) }\end{array}$} & Culture & Cultural centers quantity / quality \\
\hline & Consumption & Number of shopping centers \\
\hline & \multirow{5}{*}{$\begin{array}{l}\text { Health and } \\
\text { assistance }\end{array}$} & Degree of primary care centers coverage \\
\hline & & Degree of elderly communities coverage \\
\hline & & Degree of child communities coverage \\
\hline & & Degree of immigrant communities coverage \\
\hline & & Degree of other unprotected communities coverage \\
\hline & Transport & $\begin{array}{l}\text { Degree of connection to the center in public transport / } \\
\text { private vehicle / walking / bicycle } \\
\text { Degree of connection with other neighborhoods frequented } \\
\text { by public transport / private vehicle / walking / bicycle }\end{array}$ \\
\hline
\end{tabular}

Figure 4.

Variables required for the construction of SPUR index 

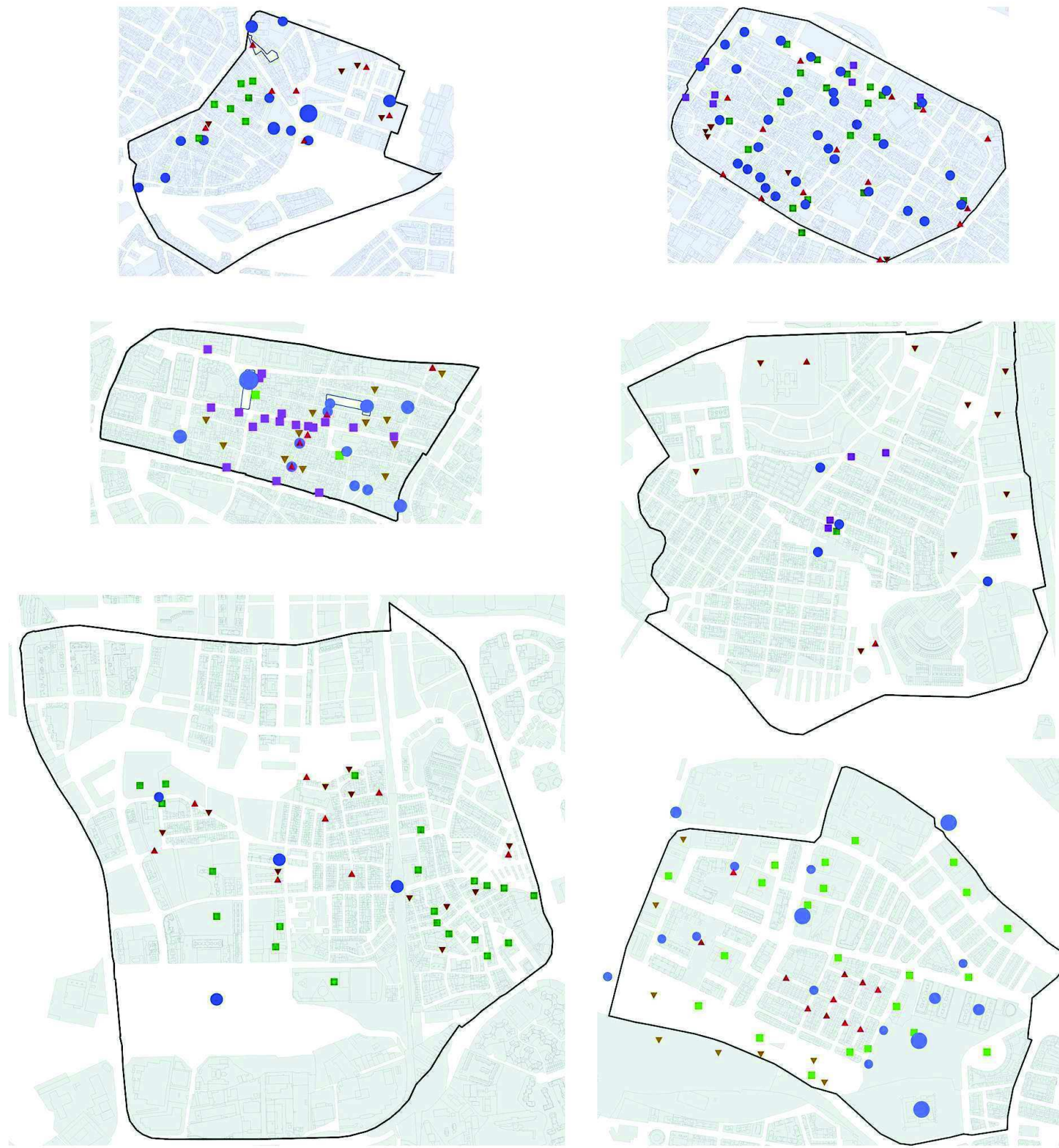

Figure 5.

Comparison between vulnerable -left- and no vulnerable -right- social perception map from different neighborhoods in Zaragoza.

the neighborhood is perceived as an area with a high Subjective Potential Urban SelfRegeneration or not.

\section{Results and discussion}

The comparison between declining areas according to National Observatory of Urban Vulnerability (quantitative approach) and the social risk areas that have been identified according to the methodology implemented in this project (Social Perception maps). Results give evidence that vulnerable neighborhoods do not correspond univocally with those in which more risk and social conflicts have been identified from a supportive social network point of view (Figure 5). Similarly, some of the neighborhoods in which there is a greater concentration of risk areas are not included in the 

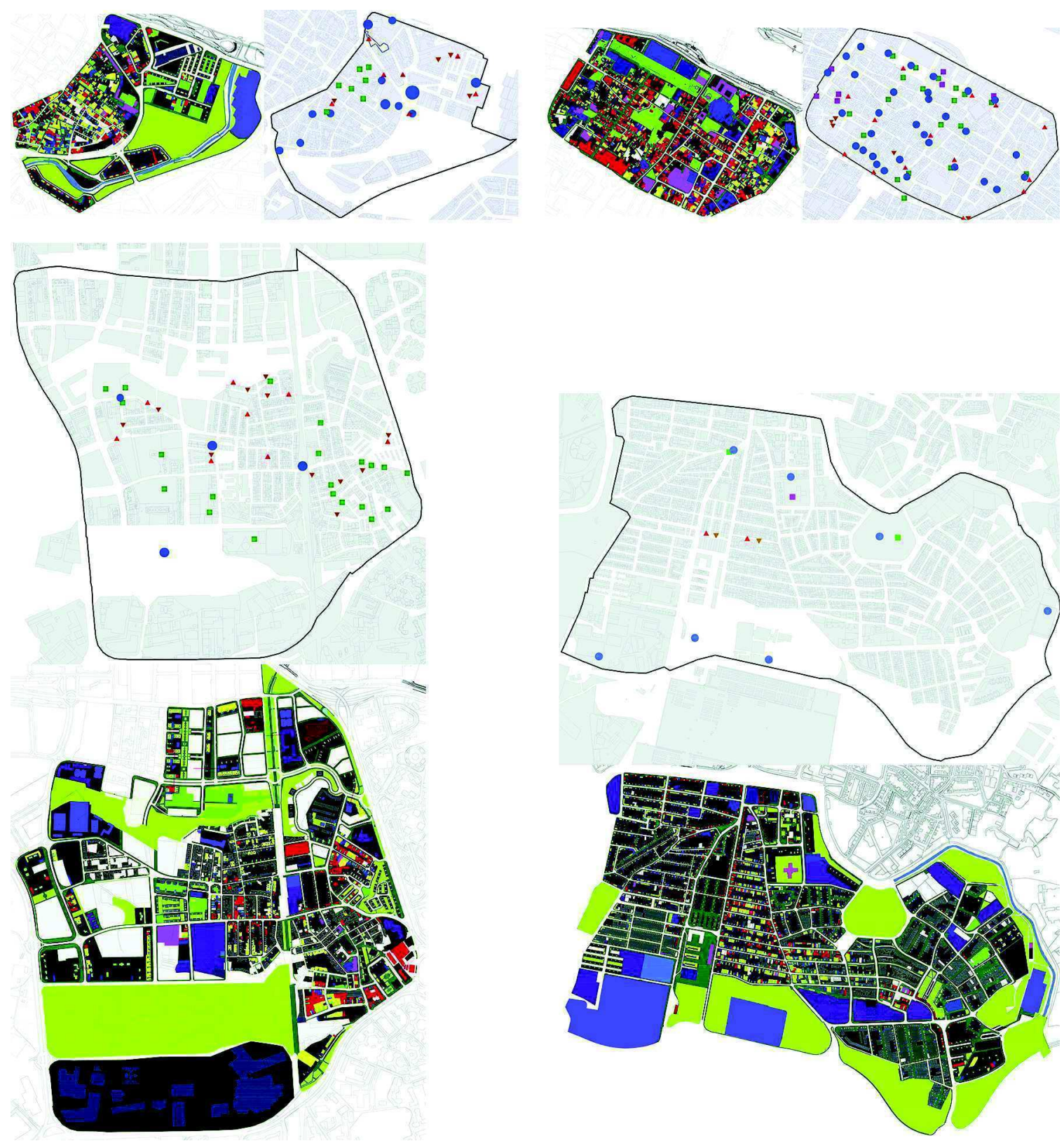

Figure 6.

Comparison between vulnerable -left- and no vulnerable -right- downtown - up- and peripheral -down- social perception and urban morphology maps from different neighborhoods in Zaragoza.

vulnerable neighborhoods catalogue provided by the National Observatory. Therefore, there is no direct correlation between social risk areas and the vulnerability status provided by the National Observatory. This result provides support for the perspective that demographic, socio-economic and residential statistics are not capable of explaining themselves potential urban self-regeneration of the public space in a neighborhood. Similarly, risk and social conflict areas prevent the creation and increase of supportive social networks. An increase of distance of urban attractors together with the fragmentation of the urban morphology, explain this fact. In other words, city does not provide socially neutral areas. If there is a no urban-attractor affected urban area, then, it will progressively turn into a risk and social conflict area.

Further, relationship between social risk areas and ground floor activities and uses in the city (commercial retail, facilities, 
open space, residential dwelling) provides evidence that urban attractors locate mainly in squares and facilities- pedestrian streets in downtown areas of vulnerable neighborhoods. However, no vulnerable neighborhoods provide a concentration of urban attractors basically in downtown commercial streets. Moreover, risk areas locate to a greater extent in residential dwellings ground floors in downtown areas of vulnerable neighborhoods. Concerning downtown areas of no vulnerable neighborhoods, risk areas locate barely in both vacant commercial retail and vacant plots.

This relationship between social risk areas and urban attractors remains the same with regard to vulnerable peripheral neighborhoods. Interestingly, it mutates with respect to peripheral no vulnerable neighborhoods. The interaction is depicted in Figure 6. Risk areas in peripheral no vulnerable neighborhoods locate in vacant plots and vacant commercial retail but they do not locate in residential dwellings ground floors. Meanwhile, urban attractors locate in a more homogeneous way, around open space, facilities and main commercial activity of the peripheral non vulnerable neighborhoods.

\section{Conclusion}

Based on the related research Social Risk Map applied to Zaragoza, at first sight, vulnerable neighborhoods do not show a decreasing trend of social support networks in comparison with no vulnerable neighborhoods. The scenario is more complex.

Vulnerable neighborhoods are not always where the social risk areas concentrate or where the more non-accessible or physically damaged urban areas locate. In fact, some of the neighborhoods that are not included in the vulnerable neighborhoods catalogue provided by the National Observatory of Urban Vulnerability demonstrate an intense social support network and active neighbors in terms of proposing activities. Besides, some vulnerable neighborhoods give evidence of a social support network as weak as the one from no vulnerable neighborhoods. This raises the possibility that relationship between social capital, social heterogeneity and urban vulnerability of social exclusion is not lineal nor direct. Social capital activation in a neighborhood is possible. However, social support networks requires a guaranteed accesibility to material resources through external to the community distributive mechanisms. This consideration appears to be subjected to the effectiveness of National Observatory of Urban Vulnerability analysis. Taken this into account, an alternative or complementary methodology applied to to the analysis of distressed areas may define new urban patterns. This patterns aim to identify complex relations between social capital, heterogeneity and urban vulnerability in the city. Social risk map methodology has been designed from a social perception point of view and has demonstrated to detect some specific positive patterns for the social network enhancement. Findings presented in this article have important implications for regulating urban redevelopment and regeneration. Social perception and relaciones vecinales de cotidianeidad are thought as a reliable basis for a later modeling of this activity.

\section{Acknowledgement}

This work was supported by a grant from the Spanish Ministry of Economy, Industry and Competitiveness (CSO2013-42576-R).

\section{References}

Hernández-Aja, A., Váquez-Espí, M., GarcíaMadruga, C., Matesanz-Parellada, Á., Moreno-García, E., Alguacil-Gómez, J. y Camacho-Gutiérrez, J. (2013) Análisis Urbanístico de Barrios Vulnerables. Observatorio de Vulnerabilidad Urbana de España (http://habitat.aq.upm.es/bbvv)

Álvarez-Mora, A. y Roch-Peña, F. (2010) Regeneración urbana integrada en Europa. Documento síntesis (Instituto Universitario de Urbanística, Universidad de Valladolid, Valladolid)

Alguacil, J. (2006) 'Barrios desfavorecidos: Diagnóstico de la situación española'. In F. Vidal Fernández (Ed.), V Informe FUHEM 
de políticas sociales: la exclusión social y el estado del bienestar en España (FUHEM, Madrid), 155-168.

Atkinson, A. B., Cantillon, B., Marlier, E. and Nolan, B. (2002) Social Indicators. The EU and Social Inclusion (Oxford University Press, New York).

Bruquetas, M., Moreno, F-J. y Walliser, A. (2005) La regeneración de barrios desfavorecidos (Fundación Alternativas, Madrid).

Cámara, C., León, J. and Ruiz, A. (2016) 'Mapa de Riesgo Social de Zaragoza. De técnica de gestión de poblaciones a praxis de consolidación de los comunes', in Diego, L., Fernández-Santos, J. and León, J. (ed.) Open Sourcing. Investigación y formación avanzada en arquitectura (Universidad San Jorge, Zaragoza) 77-103.

European Commission (2014) Integrated sustainable urban development. Cohesion Policy 2014-2020 (http://ec.europa. eu/regional_policy/sources/docgener/ informat/2014/urban_es.pdf)

De Miguel, Díez and Medina (1976) Tres estudios para un sistema de indicadores sociales (Fundación Foessa, Madrid), 11

García-Bueno, G. (2017) 'Capital sociourbanístico y potencial de regeneración urbana en Zaragoza', Clivatge, 5, 199-239.

Goodchild, M. (2016) 'GIS in the Era of Big Data', European Journal of Geography, http://cybergeo.revues.org/27647

Haklay, M (2013) 'Neogeography and the delusion of democratisation', Environment and Planning A, 45, 55-69.

Lefebvre, H. (1974) La production de l'espace (Anthropos, Paris).ç

Logan, J. R., and Molotch, J. (2007) Urban Fortunes: the political economy of place (University of California Press, US).

Muster S. and Murie, A. (2004) 'Social Exclusion and Opportunity Structures in European Cities and Neighbourhoods', Urban Studies, 41-8, 1441-1459.

The Ministry of Public Works and Transport (1990) Analisis urbanístico de Barrios Vulnerables en España (Madrid).

OECD (1998), Integrating Distressed Urban Areas, OECD Publishing, Paris (http:// dx.doi.org/10.1787/9789264162884-en).
Temes, R. (2014) 'Valoración de la vulnerabilidad integral en las áreas residenciales de Madrid', EURE, revista lationamericana de estudios urbano regionales $119,119-149$.

Torres, H. (1993) El mapa social de Buenos Aires 1940-1990 (FADU-UBA, Buenos Aires).

Rana,S.andJoliveau,T.(2009) 'NeoGeography: an extension of mainstream geography for everyone made by everyone?', Journal of Location Based Services, 3, 75-81.

Raya, E. (2010) 'Aplicaciones de una herramienta para el diagnóstico y la investigación en exclusión social', Documentos de Trabajo Social, 48, 117-136.

Ruiz, A. y Alfaro, P. (2017) 'Áreas de rehabilitación en la ciudad de Zaragoza: noción, encaje urbanístico y criterios de selección', Clivatge, 5, 170-198. 